\title{
Frontières
}

\section{Comment comprendre l'augmentation des suicides au Québec ?}

Volume 12, numéro 1, automne 1999

Suicides, générations et culture

URI : https://id.erudit.org/iderudit/1074500ar

DOI : https://doi.org/10.7202/1074500ar

Aller au sommaire du numéro

Éditeur(s)

Université du Québec à Montréal

ISSN

1180-3479 (imprimé)

1916-0976 (numérique)

Découvrir la revue

Citer ce document

(1999). Comment comprendre l'augmentation des suicides au Québec ?

Frontières, 12(1), 7-7. https://doi.org/10.7202/1074500ar d'utilisation que vous pouvez consulter en ligne.

https://apropos.erudit.org/fr/usagers/politique-dutilisation/ 


\section{«Comment comprendre l'augmentation des suicides au Québec?»}

C'est la question que la direction de Frontières a posée à quelques «éclaireurs». Non pas forcément des experts dans le domaine du suicide, mais des gens de chez nous qui pouvaient offrir une vision extérieure, mais sensible, sur cette mort que l'on se donne.

\section{Quelques réflexions de...}

C'est ainsi que Luc Blanchet, Alain Cliche, Micheline de Sève, Sergio Kokis, Jovette Marchessault et Peter F. Trent ont aimablement acquiescé à notre souhait de les lire. Leur texte figure dans des encadrés semés dans les pages de ce numéro pour offrir à nos lecteurs une vision plurielle qui contribue à situer les questions de la mort au coeur des manifestations de la vie. 